\title{
EVALUATING COMMON HEMATOLOGICAL AND BIOCHEMICAL BIOMARKERS AS PREDICTORS FOR ISCHEMIC HEART DISEASES AMONG ADULT SUDANESE PATIENTS
}

\author{
Ahmed Osama Babikir ${ }^{1} \bowtie$, Osama Khder Ahmed Elmansour ${ }^{2} \bowtie$, Hamza Ahmed Mohammed Altoum $\square$ \\ ${ }^{1}$ Faculty of Medicine, Shendi University, Department of Pathology, Sudan \\ 2 Faculty of Medicine, Shendi University, Department of Internal Medicine and Rheumatology, Sudan \\ ${ }^{3}$ Faculty of Medical Laboratory Sciences, Shendi University, Sudan
}

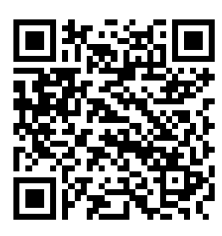

Received 21 January 2022

Accepted 25 February 2022

Published 07 March 2022

\section{CorrespondingAuthor}

Ahmed Osama Babikir,

brolykarrar@gmail.com

DOI

10.29121/granthaalayah.v10.i2.2022 .4491

Funding: This research received no specific grant from any funding agency in the public, commercial, or not-for-profit sectors.

Copyright: (C) 2022 The Author(s). This is an open access article distributed under the terms of the Creative Commons Attribution License, which permits unrestricted use, distribution, and reproduction in any medium, provided the original author and source are credited.

\section{ABSTRACT}

Background: Ischemic heart diseases are the leading cause of death worldwide. It accounts for $(20.07 \%)$ of total deaths with a death rate of 279.01 per 100.000 population. Being multifactorial in origin, the causes, diagnosis, prevention, control, and/or treatment of IHD remain active fields of biomedical research with considerable emphasis on the relativity of various risk factors and IHD.

Methods: This is a descriptive cross-sectional case-control prospective analytical study to evaluate the hematological and biochemical predictors in ischemic heart disease patients in Shendi locality, River Nile, State Sudan. The study excluded all patients with comorbidities that might affect the results of biomarkers.

Results: The mean values of $\mathrm{Hb}, \mathrm{PCV}, \mathrm{RBCs}, \mathrm{MCV}, \mathrm{MCH}, \mathrm{MCHC}, \mathrm{RDW}$ in case group were $(12.3 \mathrm{~g} / \mathrm{dl}),(37.7 \%),\left(4.2 \times 10^{12} / \mathrm{l}\right),(87.9 \mathrm{fl}),(28.9 \mathrm{pg}),(32.9 \mathrm{~g} / \mathrm{dl})$ and $(16.5)$ respectively and mean of TWBCs, Neutrophil, lymphocyte, monocyte, eosinophil, basophil, platelet count and MPV of (8.4 x 109 /l), (66.6\%), (25\%), (5.9\%), (2.5\%), (0\%), (301.9 x 109 /l) and (8.4) respectively. The mean of hsCRP, D.dimer in case group were (5.896 $\mathrm{mg} / \mathrm{l}),(1247.4 \mathrm{ng} / \mathrm{ml})$, respectively. The case group had mean range of urea and creatinine $(57.68 \mathrm{mg} / \mathrm{dl})$ and $(1.55 \mathrm{mg} / \mathrm{dl})$ respectively, and mean of $\left(\mathrm{Na}^{+}\right),\left(\mathrm{K}^{+}\right)$and $\left(\mathrm{Ca}^{2+}\right)$ of $(136.1 \mathrm{mmol} / \mathrm{l}),(3.87 \mathrm{mmol} / \mathrm{l})$ and $(9.73 \mathrm{mg} / \mathrm{dl})$ respectively.

Conclusion: When compared to healthy individuals in the control group, the case group had lower $\mathrm{Hb}, \mathrm{PCV}$, red cells indices, serum sodium $\left(\mathrm{Na}^{+}\right)$, potassium $\left(\mathrm{K}^{+}\right)$, and calcium $\left(\mathrm{Ca}^{2+}\right)$ levels. And higher levels of TWBCs, Neutrophil, platelet, MPV, Serum hsC-reative protein, plasma D.dimer, b.urea, and serum creatinine.

Keywords: Ischemic Heart Diseases, Biomarkers, Inflammatory Markers, Atherosclerosis

\section{INTRODUCTION}

Ischemic heart diseases (IHD) are the number one cause of death, disability, and human suffering globally. It affects around 126 million individuals $(1,655$ per 100,000 ), which is approximately $1.72 \%$ of the world's population. Near nine million deaths are caused by IHD globally. With higher rates among men than women of a given age, CHD also carries a higher case-fatality rate among the male gender Khan et al. (2020). According to the latest WHO data published in 2018 IHD related deaths accounted for $(20.07 \%)$ of total deaths with a death rate of 279.01 per 100.000 of the population Healthdata.org (2019). Numerous risk factors have been implicated in the disease process, morbidity and mortality, age, 
gender, hypertension, diabetes, serum cholesterol levels, smoking, and excessive alcohol consumption NPS Medicine wise (2011), Norhammar et al. (2004), with a variable individual contribution of each risk factor between different communities or ethnic groups and remarkably strong consistency of the overall contribution of these risk factors to epidemiological studies. Bertazzo et al. (2013)

A biomarker is tool used in predicting, diagnosing, and staging diseases, thus help effectively manage patients by the provision of prompt and accurate treatment and/or prognosis Biomarkers Definitions Working Group (2001), Yilmaz et al. (2010). A biomarker may be measured on a bio-sample (as a blood, urine, or tissue test), recorded (blood pressure, electrocardiogram, or Holter), or it may be an imaging test (echocardiogram). A vast array of biomarkers maybe added to conventional cardiovascular risk factors in predicting the risk of future CVD; however, the clinical value of some biomarkers is still questionable Threapleton et al. (2013). Currently, biomarkers that may reflect a higher risk of CVD include coronary artery calcification, carotid intima-media thickness, higher fibrinogen, and PAI-1 blood concentrations. elevated homocysteine, elevated blood levels of asymmetric dimethylarginine, Inflammation as measured by CRP, elevated LDL levels, and elevated blood levels of (BNP).Cihat et al. (2012)

\section{MATERIALS AND METHODS}

Study design: This is a descriptive cross-sectional case-control prospective analytical study to evaluate the haematological and biochemical predictors in ischemic heart disease patients at Almak Nimir University Hospital; a Shendi University-affiliated tertiary hospital in Sudan. Study population: A total of (100) samples were collected from the Study group of ischaemic heart disease patients and (100) samples were collected from healthy individuals as a control group. Inclusion criteria: Patients of both sexes with ischaemic heart disease (who take drugs or not take), irrespective of treatment patients with no other medical conditions were included in the study.

Exclusion criteria: Patients with other comorbid diseases such as renal failure, liver disease, haematological diseases and other medical conditions or receiving certain treatment that affect the results were excluded from the study. Data was collected using a self-administrated pre-coded questionnaire which was specifically designed to obtain information that helped in the study then analysed using SPSS version 11.5. (Mean, standard deviation, standard error mean, P. value by using independent T.test).

CBC was done by using Mindray Hematology Analyzer (Mindray bc-3000); every film was first inspected at low power (x10) before the general examination was undertaken with the $\mathrm{x} 40$ lenses. The $\mathrm{x} 100$ oil immersion lens is generally reserved for examining. B. urea, S.creatinine and S. Ca2+ using automated chemistry analyzer, Mindray BS 120). Estimation of serum electrolyte using an ion-selective electrode. hs C.reactive protein and D.dimer were measured via sandwich immunodetection.

\section{RESULTS}

A total of (100) blood sample collected from ischaemic heart disease patients and (100) samples collected as control from healthy individuals include frequency of sex was 32 males (32\%) and 68 females (68\%), frequency of age groups 40-80 years $95(95 \%)$. Frequency of weight (50-100) $\mathrm{kg}$ (97\%) in the study group. 
The average age of patients with ischaemic heart disease in the study was (61.44 \pm 10.851$)$, with a range of (40-80) years.

The majority of our patients (68) were of female gender (68\%), and $32(32 \%)$ were males. Regarding to weight, the average weight of patients with ischaemic heart disease in the study was $(68.08 \pm 11.912)$, with a range of $(50-100 \mathrm{~kg})$.

\begin{tabular}{|c|c|c|c|}
\hline \multicolumn{2}{|c|}{ Characteristic } & \multirow{2}{*}{$\begin{array}{c}\text { Frequency } \\
100\end{array}$} & \multirow{2}{*}{$\begin{array}{c}\text { Percent \% } \\
50 \%\end{array}$} \\
\hline Study groups & Case & & \\
\hline & Control & 100 & $50 \%$ \\
\hline \multirow[t]{2}{*}{ Sex } & Male & 32 & $32 \%$ \\
\hline & Female & 68 & $68 \%$ \\
\hline \multirow[t]{3}{*}{ Age/yrs } & $<40$ yrs. & 2 & $2 \%$ \\
\hline & $40-80$ yrs. & 95 & $95 \%$ \\
\hline & $>80$ yrs. & 3 & $3 \%$ \\
\hline \multirow[t]{3}{*}{ Weight/kg } & Less than $50 \mathrm{~kg}$ & 2 & $2 \%$ \\
\hline & $50-100 \mathrm{~kg}$ & 97 & $97 \%$ \\
\hline & More than $100 \mathrm{~kg}$ & 1 & $1 \%$ \\
\hline
\end{tabular}

Participation to risk factors to ischaemic heart disease reflected that; 64 (64\%) were HTN patients, while 36 (36\%) were not. On the other hand, 32 (32\%) were DM patients, while the remaining $68(68 \%)$ were not.

Furthermore, $4(4 \%)$ of the patients were smokers, while $96(96 \%)$ of them were not. Concerning obesity, 24 (24\%) of patients were obese, 76 (76\%) with normal weight. Regarding family history, most of the patients $92(92 \%)$ with no family history of ischemic heart disease and 8 (8\%) were family history. Table 2

\begin{tabular}{|cccc|}
\hline \multicolumn{3}{|c}{ Table 2 Distribution of Study Population According to Risk Factors } \\
\hline Characteristic & & Frequency & Percent \% \\
\hline HTN & Yes & 64 & $64 \%$ \\
\hline No & 36 & $36 \%$ \\
\hline Smoking & Yes & 32 & $32 \%$ \\
\hline & No & 68 & $68 \%$ \\
\hline Lipidaemia & Yes & 4 & $4 \%$ \\
\hline & No & 96 & $96 \%$ \\
\hline Family history & No & 24 & $24 \%$ \\
& Yes & 8 & $76 \%$ \\
\hline & No & 92 & $8 \%$ \\
\hline
\end{tabular}

The mean values of $\mathrm{Hb}, \mathrm{PCV}, \mathrm{RBCs}, \mathrm{MCV}, \mathrm{MCH}, \mathrm{MCHC}$, RDW in case group were $(12.3 \mathrm{~g} / \mathrm{dl}),(37.7 \%),\left(4.2 \times 10^{12} / \mathrm{l}\right),(87.9 \mathrm{fl}),(28.9 \mathrm{pg}),(32.9 \mathrm{~g} / \mathrm{dl})$ and $(16.5)$ respectively and in control group the mean values of $\mathrm{Hb}, \mathrm{PCV}, \mathrm{RBCs}, \mathrm{MCV}, \mathrm{MCH}$, MCHC, RDW were (13.1 g/dl), (39.8\%), (4.4x1012/l), (89.0 fl), (29.2 pg), (32.8 g/dl) and (15.6) respectively. Table 3. 


\begin{tabular}{|c|c|c|c|c|c|}
\hline Groups & & Number & Mean & SD & P. value \\
\hline \multirow[t]{2}{*}{$\mathrm{Hb} \mathrm{g/dl}$} & Case & 100 & 12.3 & 1.59 & 0.003 \\
\hline & Control & 100 & 13.1 & 1.88 & \\
\hline \multirow[t]{2}{*}{ RBCsx $10^{9}$} & Case & 100 & 4.23 & 0.519 & 0.001 \\
\hline & Control & 100 & 4.48 & 0.55 & \\
\hline \multirow[t]{2}{*}{ PCV \% } & Case & 100 & 37.7 & 4.20 & 0.002 \\
\hline & Control & 100 & 39.8 & 5.13 & \\
\hline \multirow[t]{2}{*}{ MCV fl } & Case & 100 & 87.9 & 6.71 & 0.199 \\
\hline & Control & 100 & 89.0 & 4.53 & \\
\hline \multirow[t]{2}{*}{ MCH pg } & Case & 100 & 28.9 & 2.63 & 0.444 \\
\hline & Control & 100 & 29.2 & 1.78 & \\
\hline \multirow[t]{2}{*}{ MCHC g/dl } & Case & 100 & 32.9 & 1.86 & 0.707 \\
\hline & Control & 100 & 32.8 & 0.76 & \\
\hline \multirow[t]{2}{*}{ RDW } & Case & 100 & 16.5 & 2.53 & 0.000 \\
\hline & Control & 100 & 15.6 & 0.68 & \\
\hline
\end{tabular}

The mean of TWBCs, Neutrophil, lymphocyte, monocyte, eosinophil, basophil, platelet count and MPV in IHD were (8.4 x 109 /l), (66.6\%), (25\%), (5.9\%), (2.5\%), (0\%), (301.9 x 109/l) and (8.4) respectively. the mean of TWBCs, Neutrophil, lymphocyte, monocyte, eosinophil, basophil, platelet count and MPV in control were (5.7 x 109 /), (48.1\%), (43.2\%), (6.1\%), (2.6\%), (0\%), (277.5 x 109/1) and (9.1) respectively. Table 4

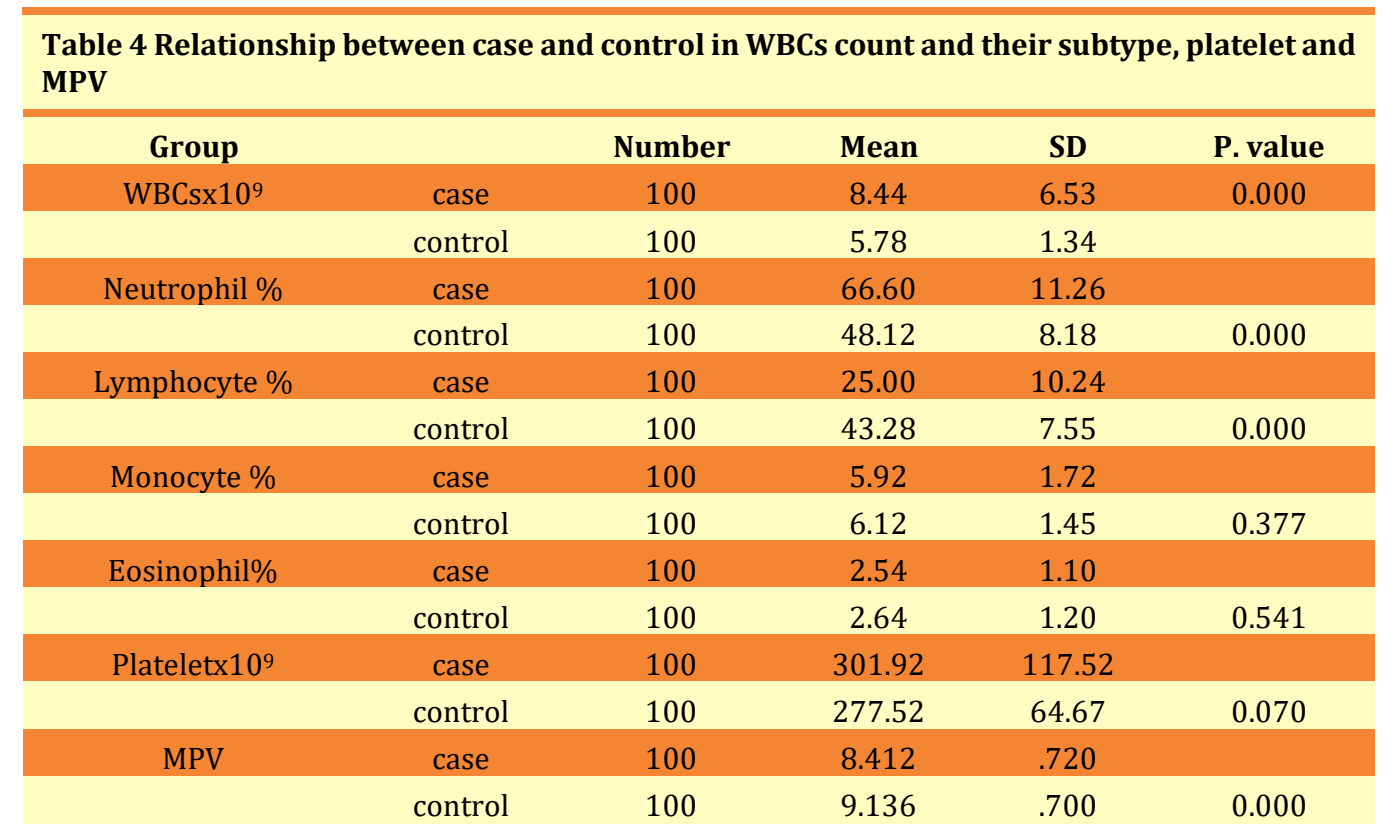

The mean of hsCRP, D.dimer in case group were $(5.896 \mathrm{mg} / \mathrm{l}),(1247.4 \mathrm{ng} / \mathrm{ml})$, respectively. The mean of hsCRP, D.dimer in control group were $(0.37 \mathrm{mg} / \mathrm{l}),(90.08$ $\mathrm{ng} / \mathrm{ml}$ ), respectively. Table 5 


\begin{tabular}{|c|c|c|c|c|c|}
\hline Group & & Number & Mean & SD & P. value \\
\hline \multirow[t]{2}{*}{ Hs-CRP mg/dl } & case & 100 & 5.89 & 3.77 & \\
\hline & control & 100 & 0.37 & 0.44 & 0.000 \\
\hline \multirow[t]{2}{*}{ D. dimer $\mathrm{ng} / \mathrm{dl}$} & case & 100 & 1247.44 & 2583.21 & \\
\hline & control & 100 & 90.08 & 25.60 & 0.000 \\
\hline
\end{tabular}

The mean of urea and Creatinine in case group were $(57.68 \mathrm{mg} / \mathrm{dl})$ and $(1.55$ $\mathrm{mg} / \mathrm{dl})$ respectively. The mean of urea and Creatinine in control were $(30.00 \mathrm{mg} / \mathrm{dl})$ and $(1.18 \mathrm{mg} / \mathrm{dl})$ respectively. Table 6

\begin{tabular}{|c|c|c|c|c|c|}
\hline \multicolumn{6}{|c|}{ Table 6 Comparison between case and control in urea and creatinine } \\
\hline Group & & Number & Mean & SD & P. value \\
\hline \multirow[t]{2}{*}{ Urea mg/dl } & Case & 100 & 57.68 & 42.742 & 0.000 \\
\hline & Control & 100 & 30.00 & 12.358 & \\
\hline \multirow[t]{2}{*}{ Creatinine mg/dl } & Case & 100 & 1.556 & 1.4612 & 0.020 \\
\hline & Control & 100 & 1.184 & 0.6141 & \\
\hline
\end{tabular}

The mean of $\left(\mathrm{Na}^{+}\right),\left(\mathrm{K}^{+}\right)$and $\left(\mathrm{Ca}^{2+}\right)$ in case group were $(136.1 \mathrm{mmol} / \mathrm{l}),(3.87$ $\mathrm{mmol} / \mathrm{l})$ and $(9.73 \mathrm{mg} / \mathrm{dl})$ respectively. The mean of $\left(\mathrm{Na}^{+}\right),\left(\mathrm{K}^{+}\right)$and $\left(\mathrm{Ca}^{2+}\right)$ in control group were (136.1 mmol/l), $(3.87 \mathrm{mmol} / \mathrm{l})$ and $(9.73 \mathrm{mg} / \mathrm{dl})$ respectively. Table 7.

\begin{tabular}{|cccccc|}
\hline \multicolumn{5}{|c|}{ Table 7 Comparison between case and control in electrolyte } \\
\hline Group & & Number & Mean & SD. Deviation & P.value \\
\hline$\left(\mathrm{Na}^{+}\right) \mathrm{mmol} / \mathrm{l}$ & case & 100 & 136.12 & 5.05 & \\
& control & 100 & 138.44 & 2.98 & 0.000 \\
\hline$\left(\mathrm{K}^{+}\right) \mathrm{mmol} / \mathrm{l}$ & case & 100 & 3.876 & 0.5924 & \\
& control & 100 & 4.048 & 0.3037 & 0.010 \\
\hline & case & 100 & 9.736 & 0.5684 & \\
\hline & control & 100 & 10.656 & 0.5916 & 0.000 \\
\hline
\end{tabular}

\section{DISCUSSION}

It is now well comprehended that a complex matrix of genetic, environmental, biological, and social factors contributes to the development and progression of IHD influencing the disease at all levels of encounter from risk stratification and development, to complication anticipation and outcome prognosis. Thus, it is vital to denote any variations in demographic characteristics and the relations of biomarkers to known risk factors. Batstone (1997), LaBaer (2005)

While it's well acknowledged that among middle-aged people, coronary heart disease is (2) to (5) times more common in men than in women Bridget (2011). Our study results reveal the quite opposite, in which a total of 32 males (32\%) and 68 females (68\%) represented the study group. The world health organization estimated that $(40 \%)$ of the variation in the sex ratios of coronary heart disease mortality was attributed to gender Jackson et al. (1999). One of the proposed explanations for the gender differences in CVD is hormonal difference. Studies have pointed out that Estrogen may have protective effects through glucose metabolism and the haemostatic system, and it may have a direct effect on improving endothelial cell function Linden et al. (1996). In terms of age distribution, (95\%) of the study group aged (40-80 years). It is estimated that there is approximately a tripling of 
risk of IHD with each decade of life Sergio et al. (2013), and that (82 \%) of people who die of CHD are (65yrs) and older Inaba et al. (2012).

Multiple hypotheses linked aging with ischemic heart diseases, for example the marked increase in serum total cholesterol levels with age; (45to 50 years) in males and (60 to 65 year) in females Jousilahti et al. (1999). Additionally, studies have described that the coronary vascular walls showed considerable mechanical and structural changes, causing progressively diminishing elasticity and compliance; as major contributors to IHD. Jousilahti et al. (1999), Toshio et al. (2001)

The results of this study denoted that the hypertensive patients were at high risk to IHD and showed an increased prevalence as (64\%) of the study group were found to be hypertensive, followed by diabetes as only (32\%) were diabetic. Most of the patients were non-STEMI type, with predominantly inferior, anterior ECG changes.

Our study results demonstrated that there was a significant decrease in $\mathrm{Hb}$, RBCs count, and PCV compared to control. (P-value $>0.05$ ). Results of this current study are different when compared to a study done by Toshio team in Japan which revealed that: high PCV and Hb were risk factors for IHD Puddu et al. (2002). Several factors related to RBCs are associated with IHD including Hb levels, PCV and ESR but there are not enough data to suggest a significant association between the RBCs count and cardiovascular disease. Patel et al. (2009)

The study findings prevailed a decrease in the mean of RBCs indices (MCV, MCH $\& \mathrm{MCHC}$ ) and there was no association when compared to the control group (pvalue $<0.05$ ).

With the significant increase in the mean of RDW compared to the control group, there was a strong significant statistical value depicted among the study population; (P. value 0.000$)$. These findings are in line with the study conducted by Patel VK et al, in which RDW was significantly associated with an increased risk of death secondary to CVD in cross-sectional studies of the population of the U.S Madjid and Fatemi (2013). In addition, the RDW is an independent predictor of death in patients who have had previous MI or stroke and in men referred for coronary angiography. Madjid and Fatemi (2013)

The results of this study also confirmed an increase in the mean of WBCs \& neutrophils and a decrease in lymphocytes, eosinophils \& monocytes means with a significant statistical relationship found among the study population; (P. value 0.000). Results of the present study were in agreement with a previous study done by Mohammad Madjid, and Omid Fatemi suggesting that: leucocytosis can be considered as a marker of inflammatory changes in atherosclerotic lesions. Korean (2016)

While our data implied an increase in the mean of platelet compared to the control group -with no significant statistical difference observed among the study population; $(\mathrm{P}=0.070)$ -

There was a considerable decrease in MPV mean compared to control, with strong significant statistical value demonstrated among study population; (P. value $0.000)$. It thus, appears that the role of platelets in the pathogenesis of IHD is due mainly to their functional properties and their interaction with plasma and tissue factors.

This is coherent with the findings of various similar studies such as one conducted by Dong-Hyun Choi, Seong-Ho Kang and Heesang Song showing a significant correlation between MPV, the risk of ischemic stroke in AF patients, and poor clinical outcomes after PCI in patients with coronary artery disease. Volanakis (2001) 
The results of the tests conducted showed an increase in the mean of hs-CRP compared to the control group. There was a strong significant statistical difference appeared among the study population; $(P=0.000)$. The recent study showed a strong association between hs-CRP and IHD. The results were in agreement with multiple other studies that presented an increase in CRP of IHD patients. One study denoted that: an increase in hs-CRP was associated with increased incidence of recurrent angina, coronary revascularization, and cardiovascular death. It has recently been suggested that hs-CRP is a marker of inflammation, along with serum cholesterol, which may be a critical component in the development and progression of atherosclerosis John et al. (2001). Our study also shows an increase in the mean of D.dimer compared to the control group with significant statistical differences estimated among the study population. This current study found that an increased D.dimer was associated with IHD. A pathophysiological explanation is that D.dimer is hypothesized to be involved in the so-called inflammation -coagulation -axis. The results of the present study are relevant to the previous study done by. Ostfeld et al. (2005)

The increased mean of urea \& creatinine was observed in this study to be higher than the control group. This study indicated an association between increased urea, creatinine, and IHD, in coherence with the result adopted by (Kirtane et al, 2005), suggesting that renal dysfunction has been associated with adverse cardiovascular outcomes Choudhury et al. (2011).

Finally, a significant reduction in this study in serum sodium $(\mathrm{Na}+)$, potassium $(\mathrm{K}+)$, and calcium $(\mathrm{Ca} 2+)$ levels among the IHD patients were detected and compared to healthy individuals in the control group. This finding is in an accordance with the study carried out by Choudhury et al. (2011) which depicted an effect in (K+) level in IHD patients Yilmaz et al. (2010).

\section{CONCLUSION}

Our study concluded that Hb, PCV, red cells indices were lower in IHD patients, and that TWBCs, Neutrophil, platelet, plasma D. dimer and serum hsC-reactive protein were higher when compared to healthy individuals. IHD patients also had abnormally increased renal function tests (urea and creatinine) and a lower level of sodium $(\mathrm{Na}+)$, potassium $(\mathrm{K}+)$, and calcium $(\mathrm{Ca} 2+)$ when compared to healthy individuals in the control group.

\section{REFERENCES}

Batstone G (1997). Practising by the evidence: the role of pathology. J Clin Pathol. $50: 447-448$. Retrieved from https://doi.org/10.1136/jcp.50.6.447

Biomarkers Definitions Working Group (2001). Biomarkers and surrogate endpoints : preferred definitions and conceptual framework. Clin Pharmacol Ther. $69 \quad 89-95 . \quad$ Retrieved from https://doi.org/10.1067/mcp.2001.113989

Bridget B. Kelly, (2011) editors : Institute of Medicine of the National. Promoting cardiovascular health in the developing world : a critical challenge to achieve global health. Washington, D.C. : National Academies Press; 220109780309147743. Retrieved from https://doi.org/10.1016/j.gheart.2011.08.002

Choudhury MBK, Rahman MS, Hassan MM, Begum R, Hoque N, Akhtaruzzaman M : Chowdhury AN. (2011). Comparison of Serum Magnesium and Potassium in Acute Myocardial Infarction and Chronic Ischemic Heart Disease. J. Dhaka 


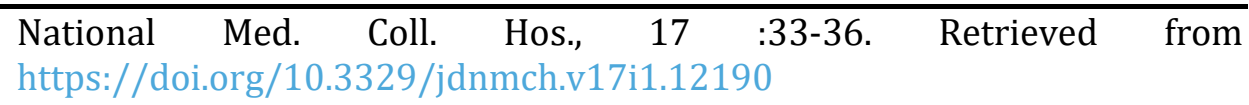

Cihat Sanli, Deniz Oguz, Rana Olgunturk, et al. (2012). Elevated homocysteine and asymmetric dimethyl arginine levels in pulmonary hypertension associated with congenital heart disease. Retrieved from https://doi.org/10.1007/s00246-012-0321-9

Healthdata.org (2019), Sudan: National institute for health ,metrics and evaluation.

Inaba, Y, Chen, JA, Bergmann, SR (2012) (January 2012 : Carotid plaque, compared with carotid intima-media thickness, more accurately predicts coronary artery disease events: à meta-analysis.. Atherosclerosis 220.1 :128-33. Retrieved from https://doi.org/10.1016/j.atherosclerosis.2011.06.044

Jackson R, Chambles L, Higgins M, Kuulasmaa K, Wijnberg L, Williams D (1999) (WHO MONICA Project, and ARIC Study.) Sex difference in ischaemic heart disease mortality and risk factors in 46 communities: an ecologic analysis. Cardiovasc Risk Factors. 7 :43-54.

John Danesh, Peter Whincup, Mary Walker, Lucy Lennon, Andrew Thomson, Paul Appleby, Ann Rumley, Gordon D.O. (2001) Low Fibrin D-Dimer and Coronary Heart Disease. Retrieved from https://doi.org/10.1161/01.CIR.103.19.2323

Jousilahti P, Vartiainen E, Tuomilehto J, Puska P (March 1999). "Sex, age, cardiovascular risk factors, and coronary heart disease: à prospective follow-up study of 14786 middle-aged men and women in Finland". Circulation. 99 (9) : 1165-72. Klatsky AL (May 2009 : Alcohol and cardiovascular diseases. Expert Rev Cardiovasc Ther 7. 5 :499-506. Retrieved from https://doi.org/10.1161/01.CIR.99.9.1165

Korean J (2016). Intern Med., 31 :1009-1017. Retrieved from https://doi.org/10.3904/kjim.2016.078

LaBaer J (2005) So, you want to look for biomarkers. J Proteome Res., 4 :1053-1059. Retrieved from https://doi.org/10.1021/pr0501259

Linden W, Stossel C, Maurice J (1996). BMJ (Clinical research ed.) 345 : e3953. PMC 3392078. PMID 227 (April 1996 : Psychosocial interventions for patients with coronary artery disease : à meta-analysis. Arch. Intern. Med. 156. 7 :745-52. Retrieved from https://doi.org/10.1001/archinte.1996.00440070065008

Mohammad Madjid, and Omid Fatemi (2013) Components of the Complete Blood Count as Risk Predictors for Coronary. Heart DiseaseTex Heart Inst J., 40 :1729.

Moien AB Khan, Muhammad Jawad Hashim, Halla Mustafa, et al. (2020). Global Epidemiology of Ischemic Heart Disease: Results from the Global Burden of Disease Study. Cureus. 12 :9349. Retrieved from https://doi.org/10.7759/cureus.9349

NPS Medicinewise (1 March 2011). "NPS : Prescribing Practice Review 53 : Managing lipids". Retrieved 1 August. 2011.

Norhammar A, Malmberg K, Diderhol E, et al. (2004). Diabetes mellitus: the major risk factor in unstable coronary artery disease even after consideration of the extent of coronary artery disease and benefits of revascularization. J. Am Coll Cardiol. 43 :585-591. Retrieved from https://doi.org/10.1016/j.jacc.2003.08.050 
Patel KV, Ferrucci L, Eeshler WB, Longo DL, Guralnik JM (2009). Red blood. 515-23. Retrieved from https://doi.org/10.1001/archinternmed.2009.11

Puddu PE, Lanti M, Menotti A, et al. (2002) Red blood cell count in short -term prediction of cardiovascular disease incidence in the Gubbio population study. Acta cardiol, 57 :177-85. Retrieved from https://doi.org/10.2143/ac.57.3.2005387

Robert Ostfeld, Michael Spinelli, Disha Mookherjee, et al. (2005). The association of BUN levels and coronary heart disease, albert Einstein college of medicine.

Sergio Bertazzo, Eileen Gentleman, Kristy L. Cloyd, et al. (2013) Nano-analytical electron microscopy reveals fundamental insights into human cardiovascular tissue calcification. Nature Materials. 12 :576-583. Retrieved from https://doi.org/10.1038/nmat3627

Threapleton, D. E., Greenwood, D. C., Evans, et al. (2013) Dietary fibre intake and risk of cardiovascular disease: systematic review and meta-analysis. BMJ 347. 19 :6879-6879. Cite uses deprecated parameters. Retrieved from https://doi.org/10.1136/bmj.f6879

Toshio Kobayashi, Yuji Miyoshi, Kazue Yamaoka And Eiji Yano (2001). Relationship between Hematological Parameters and Incidence of Ischemic Heart Diseases among Japanese White-Collar Male Workers. Occup Health, 43 :8589. Retrieved from https://doi.org/10.1539/joh.43.85

Volanakis JE (2001), Human C-reactive protein: expression, structure, and function. Mol Immunol ,38. 189 :197. Retrieved from https://doi.org/10.1016/S0161-5890(01)00042-6

Wang TJ, Gona P, Larson MG, et al. (2006), Multiple biomarkers for the prediction of first major cardiovascular events and death. N. Engl. J. Med. 355. 25 :26319. Retrieved from https://doi.org/10.1056/NEJMoa055373

Yilmaz, N., Yegin A, Aykal G (2010), New Noninvasive Modalities in Coronary Angiography - Diagnostic Values of New Biomarkers for Cardiovascular Disease.2011. Retrieved from https://doi.org/10.5772/18213 